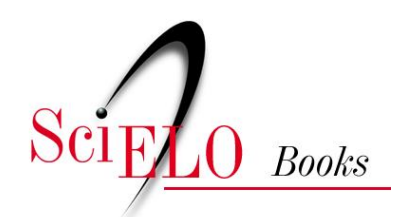

\title{
Relaciones y tensiones en los proyectos colonizadores minioneros y dirigentes shuar
}

\author{
Blas Garzón-Vera
}

\section{SciELO Books / SciELO Livros / SciELO Libros}

GARZÓN VERA, B. Relaciones y tensiones en los proyectos colonizadores: minioneros y dirigentes shuar. In: JUNCOSA BLASCO, J., and GARZÓN VERA, B., eds. Misiones, pueblos indígenas y la conformación de la Región Amazónica: actores, tensiones y debates actuales [online]. Quito: Editorial Abya-Yala, 2019, pp. 57-87. ISBN: 978-9978-10-494-1. https://doi.org/10.7476/9789978104941.0005.

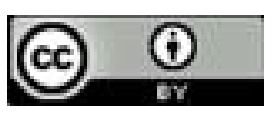

All the contents of this work, except where otherwise noted, is licensed under a Creative Commons Attribution 4.0 $\underline{\text { International license. }}$

Todo o conteúdo deste trabalho, exceto quando houver ressalva, é publicado sob a licença Creative Commons Atribição 4.0.

Todo el contenido de esta obra, excepto donde se indique lo contrario, está bajo licencia de la licencia Creative Commons Reconocimento 4.0. 


\title{
Relaciones y tensiones en los proyectos colonizadores: misioneros y dirigentes shuar
}

\author{
Blas Garzón-Vera ${ }^{1}$ \\ bgarzon@ups.edu.ec
}

\section{Introducción}

El presente artículo: "Relaciones y tensiones en los proyectos colonizadores: misioneros, colonos y dirigentes shuar", busca esclarecer las complejas relaciones que se dieron desde finales del siglo XIX hasta mediados del siglo XX, en el proceso de conformación regional de la Amazonía ecuatoriana, específicamente en el espacio territorial de la actual provincia de Morona Santiago. Varios actores fueron o siguen siendo partícipes de estos procesos: por un lado, están los nativos shuar; y de otro, quienes llegaron a sus territorios en diferentes momentos y movidos por distintos intereses. Estos fenómenos migratorios finalmente transformaron no solo el espacio geográfico sino 
toda su estructura y composición socio cultural, dotándola de una identidad particular.

El hilo conductor de esta investigación, es el trabajo misionero desplegado por la Congregación Salesiana que llega al país en 1988 por gestiones del Gobierno nacional, para hacerse cargo de la educación técnica y de las misiones en la Amazonía; esta segunda intensión, es el tema de interés de este artículo. Desde los trabajos exploratorios que realizaron los primeros misioneros en la región de Gualaquiza, el proyecto fue claro "colonizar y cristianizar" a los Shuar para que se incorporen a dinámica del Estado nacional. Se analiza como estudio de caso, la Misión-Internado de Sevilla Don Bosco, fundada el 2 de mayo de 1943, obra que se constituyó en un arquetipo, una institución modélica para nuevas fundaciones misioneras tanto en territorio shuar, como años más tarde en la zona achuar.

Contemporáneo a estos esfuerzos y en algunas zonas mucho antes de la llegada de los salesianos, existían exiguos asentamientos de población mestiza de la Sierra en estructura de fincas o pequeñas haciendas, propiedad de terratenientes cuencanos y azuayos que lógicamente apoyaron estas causas porque concordaban con sus intereses particulares.

Desde finales del siglo XIX e inicios del XX, se dan esporádicos fenómenos migratorios de la Sierra a la Amazonía, las mismas que se vuelven cada vez más frecuentes, cuando una empobrecida población serrana mira al Oriente como el sitio idóneo para la expansión del espacio agrícola a tierras de piamonte y las planicies amazónicas; y por tanto encuentran en los misioneros aliados estratégicos para asentarse en la zona.

No será hasta casi mediados del siglo XX, en que el Estado ecuatoriano inicia una presencia real en esta zona. Se había desentendido, o más bien había encargado la atención no solo espiritual y educativa a los salesianos, sino la presencia del Estado mismo en el Oriente. En estas décadas encontramos a los misioneros realizando trabajos desde infraestructuras viales (caminos, puentes, pistas de aterrizaje), infraestructura arquitectónica, centros de salud, instituciones educativas, etc.; incluso se 
hacen cargo en calidad de "tutores" del pueblo shuar a través

de dos contratos de tierras federadas con el Estado. La simbólica y real amenaza del "enemigo" del Sur (Perú), provocó a mediados del siglo XX, una presencia más estable de otras instituciones del Estado: Militares, programas colonizadores, instituciones para legalizar las tierras (IERAC), entre otras. Para la década de los 60, algunos salesianos, apartándose de primera línea que estaba a favor de procesos colonizadores, se ponen al lado del pueblo shuar e inicia una nueva dinámica en estas relaciones; ahora serán los que busquen proteger sus tierras y más adelante su propia cultura con los nuevos cambios de la misma iglesia (Concilio Vaticano II) y nuevos enfoques de disciplinas como la Antropología.

Se pretende hacer una mirada sintética de estas intenciones y concreciones colonizadoras en el suroriente ecuatoriano, dejando constancia que múltiples fueron los actores, factores y circunstancias que fermentaron estos flujos migratorios entre la Sierra y la Amazonía. Dejar también abiertas las posibilidades para nuevos trabajos que den cuenta que no son dos los grupos preponderantes en este tipo de estudios (misioneros y pueblo shuar), sino que hay otros que llegaron y se asentaron en la zona, y que hoy se han constituido en sectores con predominio de las esferas económicas, políticas y culturales de la Región. Nos referimos a poblaciones que migraron inicialmente en busca de oro, más tarde de madera, de tierra para cultivo o crianza de animales, y finalmente funcionarios públicos que una vez se asentaron las principales instituciones gubernamentales y seccionales, se necesitaba de técnicos para operar este nuevo aparataje burocrático, del cual hoy también forma parte el pueblo shuar.

\section{Misioneros vs. cultura local}

La mayoría de misioneros salesianos que trabajaron en este Vicariato en el periodo comprendido entre 1893 y 1960 provenían de Europa y específicamente de Italia (país donde nació la Congregación Salesiana). El análisis de algunos de sus 
rasgos biográficos (sobre todo su formación) nos ayudará a comprender las acciones que ellos desarrollaron con el pueblo shuar, los principios y motivaciones que impulsaron su misión y la evolución de sus métodos de trabajo. Los misioneros se guiaron también por las orientaciones recibidas de sus superiores: vicario, provicario, inspector, directores de las misiones y visitadores extraordinarios. $^{2}$

A más de los misioneros Joaquín Spinelli, Jacinto Pancheri y Francisco Mattana — todos ellos italianos llegados en la primera expedición - sobresalen el nombre de otros religiosos que a través de sus escritos nos permiten un acercamiento al contexto de la época y a sus posiciones con respecto al pueblo shuar.

En primer lugar, tenemos a Miguel Allioni quien entró a Gualaquiza en 1908 y pocos años más tarde (1912) murió en Guayaquil de fiebre amarilla, tenía 32 años. En ese corto tiempo que permaneció en las misiones recogió muchos datos etnográficos y escribió sobre la cultura shuar. De los datos biográficos de este piamontés (Italia) se conoce que en la ciudad de Turín se había dedicado al estudio de las ciencias naturales, especialmente de la botánica. En sus escritos se manifiesta un estilo de "exactitud, minuciosidad, gusto por la clasificación, descripciones sintéticas, curiosidad insaciable” (Bottasso, 1993). Fue contemporáneo de Paul Rivet, pero al parecer no conoció sus publicaciones. Sus descripciones no tienen títulos como los de su época que casi siempre se escribían con tonos tremendistas o sensacionalistas; sin embargo, en cuanto a los contenidos se evidencia la influencia de una época en lo que se refiere al concepto de civilización y del progreso y, como consecuencia, sus apreciaciones sobre los Shuar no son siempre positivas.

Cuando describió a los Shuar, Allioni puso mucho énfasis en la libertad como un valor absoluto de este pueblo. Atribuyó la poca densidad poblacional a las guerras fratricidas que o nacionales; en cambio las visitas extraordinarias provenían desde la Casa Central de los salesianos cuya sede está en Roma, directamente enviados por el rector mayor de ese momento. 
mantenían y según sus cálculos para esa época había entre 800 y 1000 familias y unos 5000 o 6000 habitantes que él ya los empezó a llamarlos shuar y no jíbaros como era también común en esos años. De sus observaciones concluyó que para los Shuar el casarse no es una cosa solemne, sino un simple episodio; constató que pueden vivir muchos años, él conoció gente que calculó con más de 100 años, y su vejez no es impotente y enfermiza, sino vivaz y viril; cada familia era autónoma y se bastaba a sí misma. Sus individuos gozaban de la misma igualdad sea con respecto a otras familias o entre sus miembros. ${ }^{3}$

Allioni también escribió sobre las creencias religiosas que tenían los Shuar, cuando describió los "soñaderos" seguramente se refería a los ritos en las cascadas - a las cuales da gran importancia también Harner en su clásico libro- (1978 [1994]). Intentó conocer la cosmovisión mitológica en este pueblo, fueron los primeros intentos a pesar de que este religioso tenía una formación especializada en este campo.

Por otro lado, el misionero Telésforo Corbellini, fue el primero en valorar como positiva la "agresividad shuar" en función de su defensa y dio una explicación de las guerras fratricidas que los circundaban. ${ }^{4}$ En la década de los cincuenta dejó el siguiente texto: "Indicaciones para la formación de un museo nacional" (AHMS /3 VV, 3), estas iniciativas no fueron específicamente con el propósito de valorar y mostrar la riqueza de la cultura shuar, tenían más bien fines propagandísticos explícitos, de todas maneras dejó material de consulta importante. Telésforo Corbellini nació en Galgagnano (Italia) en 1884 y viajó a Ecuador en 1912. Trabajó en la misión de Méndez entre

3 Otra característica de este pueblo es la "igualdad perfecta de todas las familias, más aún, de todos los individuos. Cada cual vale lo que su valor personal... el prestigio del cual goza un jívaro, lo debe únicamente a sus acciones".

4 "Casi diría que en el jívaro esta pasión [el odio] es como la consecuencia de su hondo amor por el bien: el que no es bueno no puede ser amado y debe ser odiado... En cambio al Jívaro malhechor hay que eliminarlo... una vez que se lo haya reconocido como malo y hacedor de maldad, se pronuncia la sentencia de muerte. No existe autoridad, no existe juez... Con la sentencia... venga la muerte, y así las matanzas se suceden de ambas partes..." 
1916 y 1947. Introdujo nuevos cultivos e implementó talleres. Luchó en defensa de la tierra de los Shuar y fue una figura fundamental en la organización de los primeros internados, murió en 1953. Lo que se puede destacar al leer algunos de los párrafos de Corbellini es el tono positivo y optimista con que narró las costumbres shuar, el esfuerzo para entenderlas, la preocupación por desvanecer prejuicios. Sus textos los escribió por 1945, allí describe las obligaciones de la pareja y la posición de la mujer, la relación entre hombre-mujer y con sus padres. ${ }^{5}$

Se evidencia ya en Corbellini un cambio de actitud y mirada del pueblo shuar al momento de destacar las características de su cultura y sus valores. Cuando se auto-interrogó si la raza jíbara es nómada, escribió:

(...) creo que no se puede contestar afirmativamente. El Jívaro no va vagando por la selva para vivir solo de la caza, de la pesca o de los productos espontáneos del monte; en cambio construye la casa, cultiva la tierra, y cría animales domésticos. Tiene muy arraigado el concepto de propiedad y de respeto por la propiedad de los varios miembros de la familia (...). (en Juncosa, 1993, p. 200)

Corbellini dejó mayoritariamente escritos sobre las relaciones familiares, relaciones de parentesco (padres-hijos, esposos), relaciones sociales, sus costumbres, el aspecto religioso, "supersticiones" de los Shuar, etcétera.

Otro misionero a considerarse es el padre Carlos Crespi; sus descripciones sobre el pueblo shuar tuvieron fines propagandísticos y con rasgos exagerados. Este misionero incursionó en muchas áreas, escribió un guion documental para difundir la vida del pueblo shuar y de la labor misionera de los salesia-

"Mientras que la hija está sujeta a una vigilancia severa y viene entrenada para los trabajos domésticos, el hijo, más avanza en los años y más goza de libertad: lo vemos salir de casa, ir donde otras familias, tomar compromisos por su cuenta. Goza también de libertad en buscarse y escoger la esposa. No puede hacer lo mismo la hija para buscar o escoger al marido. Ella está siempre bajo la vigilancia de los papás, o de los tutores, si no están los papás..." 
nos. Fue partidario de una colonización extranjera ${ }^{6}$ con el afán de "civilizar" a los shuar. En otros escritos describió al pueblo shuar buscando resaltar ciertos ideales acordes al contexto nacional del momento. ${ }^{7}$ Describió también aspectos fisiológicos:

El jívaro tiene porte fiero, noble, estatura regular; mide un metro sesenta, un metro setenta y hay individuos que miden de alto $1,82 \mathrm{~m}$. y 1,92 m. Tiene el sentido del olfato poco desarrollado. La vista, empero, es finísima: distingue un pajarito a muchos metros de distancia. El gusto lo tiene muy ordinario, pero el tacto muy sensible. (Bottaso, 1982, p. 411)

Dejó escritos sobre las enfermedades más frecuentes de los shuar y sus formas de curación mediatizadas por el brujo o uwishin. En el campo científico (botánica) descubrió nuevas especies vegetales, particularmente helechos.

De autoría del padre Crespi es la película Los invencibles Shuaras del Alto Amazonas, de 1926, por primera vez y con la ayuda de un cineasta italiano fijó en el celuloide paisajes y escenas de la misión y sobre todo las costumbres del pueblo shuar (este material es considerado hoy como el primer documental antropológico ecuatoriano). Con esta película recorrió los Estados Unidos en búsqueda de recursos económicos para las misiones amazónicas. Al igual que el resto de religiosos de su época, su propuesta para el Oriente fue la transformación de la cultura shuar por medio de una educación sobre todo técnica agrícola ${ }^{8}$ y proyectos de colonización. ${ }^{9}$

6 "Yo creo no exagerar al decir que si una fuerte colonización empezase la conquista pacífica del Oriente, los jívaros en pocos años serían absorbidos por las nuevas energías $\mathrm{y}$, sin cambiar radicalmente sus costumbres, se convertiría en una fuerza verdaderamente productora para la nación...", citado por Bottasso (1982, pp. 375-377).

7 "La raza jívara se distingue muchísimo de las otras razas indígenas del Ecuador, por sus tradiciones, costumbres e idioma. Habitan en el Oriente ecuatoriano, entre el río Pastaza, Morona y Santiago. Su idioma es muy distinto del de los demás indios...". paración de los shuar y en Cuenca una escuela de formación para el personal que actuaría en las misiones, los coadjutores (Carollo 1987, p. 132).

9 “Los misioneros salesianos están convencidos que solamente después de muchos años y muchas generaciones podrían civilizar a la raza jíbara, y que eso sólo se po- 
Por otro lado, tenemos la visión de los obispos, quienes daban los lineamientos para el trabajo con los Shuar. El primer obispo, monseñor Costamagna, creyó que para lograr resultados con los Shuar se tenía que trabajar con los niños, ${ }^{10}$ impulsó la creación de los centros educativos e incluso podríamos decir que ya proyectó los futuros internados, ${ }^{11}$ motivando a los misioneros a un trabajo esforzado en esta dirección. En su breve visita de 1902, Mons. Costamagna encargó a los misioneros componer un catecismo que fue publicado en Lima en 1903, con el título "Shiori cristiano"; en las otras dos visitas que se le permitió, se dedicó al estudio de la lengua shuar. Su provicario, C. Santinelli, ordenó que "todos aprendieran la lengua de los salvajes” (Bottasso, 2011, p. 69). De igual forma, encargó al padre Alvino Del Curto la exploración y la posterior construcción de un camino que uniría la Sierra con la Amazonía, con la finalidad de favorecer el comercio y la entrada de los colonos (Barrueco, 1996, p. 105).

Unos años más tarde, el segundo obispo, monseñor Domingo Comín, incentivó el conocimiento de la cultura shuar ${ }^{12}$ a fin de poderla comprender, con la intensión siempre de buscar la conversión del pueblo shuar. En todo caso, motivados por estos llamados, muchos misioneros se dedicaron a estudiar la cul-

drá conseguir con una fuerte colonización blanca y extranjera...: Civilizar colonizando". Texto atribuido a Carlos Crespi o por su influencia, en: Bottasso (1982, p. 108).

10 "El trabajo de las misiones, se reduce casi siempre a cultivar a los hombres del mañana, los niños (...) Venga pronto el día en que cada centro de misión tenga un plantel de educación de niños, cueste lo que cueste" (AHMS. N, G. 21).

11 "Nuestras esperanzas se fincan en los niños. Lamentablemente en la actualidad tenemos solo tres: pero usted, Don Rúa, sabrá comprender cuáles y cuántas dificultades se encuentran para tenerlos siempre con nosotros. Pero, una vez que se han encariñado y acostumbrado a una vida más singular, esto les gusta inmensamente. Joaquín Bosco, José María Rúa y el pequeño Katipi no se alejarían por todo el oro del mundo..." (Boletín Salesiano de 1904, citado por: Bottasso, 1993, p. 142).

"Ustedes están en las selvas para predicar el Evangelio... Se trata de realizar una especie de injerto. ¿No será necesario conocer la planta en la que se hace el injerto, para poderlo realizar bien? Ustedes deben conocer a los jívaros. Muchos años de trabajo estéril, ¿no se deben tal vez al desconocer nosotros a estos seres que queremos hacer cristianos? Así que deben trabajar para conocerlos en sus creencias, sus leyes, sus tradiciones, en todo (...). Puede ser también que encuentren algo que no sea de destruir, sino de orientar para su mayor bien" (AHMS / VII Cm). 
tura shuar, por cuyos trabajos y de otros investigadores sociales hoy conocemos cómo era este pueblo a mediados del siglo XX. Mons. Comín llegó a Ecuador en 1901 y se había desempeñado en otros cargos: inspector y provicario de la Misión. Al momento de asumir el cargo tenía 46 años de edad y antes de ser obispo no había trabajado en las misiones. Según el padre Juan Vigna (que era su provicario), "él confiaba poco en la posibilidad de una evangelización directa y creía que los shuar cambiarían solo por la lenta acción de contacto con la población mestiza" (Bottasso, 2011, p. 70).

Será ya avanzada la década de los cuarenta, cuando se nota en los escritos misioneros, una atención más directa en el estudio de la cultura shuar, esta vez por la amenaza eminente de extinción cultural de este pueblo. El Padre Juan Vigna cuando fue provicariato en 1941 se propuso que la documentación de la cultura shuar fuera una preocupación de todos los misioneros. Con motivo de las celebraciones del cincuentenario de las Misiones Salesianas en Ecuador, lanzó en 1944 un concurso para que se estudiara "la raza y la civilización jíbara" ${ }^{13}$ Este misionero percibió como trágico el sucumbir de la cultura shuar. Los trabajos presentados fueron solamente dos de los padres Juan Ghinassi y Telésforo Corbellini.

Otros misioneros que contribuyeron al conocimiento de la cultura shuar fueron: Elías Brito, ${ }^{14}$ ecuatoriano; Juan Ghinassi, italiano; ${ }^{15}$ y Ángel Rouby. Este último, joven misionero nacido en Parma —Italia- en 1908, llegó los 18 años. Fue el más entusiasta en visitar a los Shuar de la orilla izquierda del

13 "Si no nos damos prisa para reunir todo lo que pueda interesar de la raza jíbara, después de poco no será posible decir de ella más que lo que por referencia se constatará, a modo de tradición, y esto maleado por el reflejo de la nueva civilización, que está haciendo desaparecer la raza" (Circular del padre Juan Vigna de 1945, AHMS / VII Cm).

14 Cfr. Su principal escrito: Elías Brito (1935). Sus II tomos permanecen en el AHMS de Quito y contienen mucha información testimonial de la época con clara tendencia de exaltación del trabajo de esta Congregación.

15 Entró a la Congregación Salesiana en 1926. Se dedicó al estudio de la lengua Shuar, llegando a dominarla con soltura... Se hizo conocer dentro y fuera del Ecuador con la "Gramática y Diccionario Shuar" de 1938 (Bottasso, 1982, p. 412). 
Upano. Falleció en 1939 ahogado en el río Unda Mangosiza. Por su interés y el de otros misioneros, los salesianos decidieron abrir una misión al margen izquierdo del río Upano, lo que hoy es Sevilla Don Bosco. Rouby llegó a dominar el idioma shuar (Bottasso, 1982, p. 129) pero no publicó sus estudios.

También dejaron sus aportes: Isidoro Formaggio, italiano, quien en 1950 realizó la primera película a color con reconstrucciones de la vida de los Shuar y al igual que la película de Carlos Crespi lo hizo con un criterio propagandístico y folklórico; Lino Rampón, ecuatoriano, fundador del CMIC; $;{ }^{16}$ Alfredo Germani ${ }^{17}$ (2016, p. 9) conoció la lengua shuar, estructuró su gramática y dejó escritos en el campo etnohistórico; Luis Carollo, nació en Thiene - Italia — en 1923, llegó a Ecuador en 1938 con 15 años de edad. Su primera misión fue Limón, estudió teología en Quito y se ordenó sacerdote en 1951. Ocupó el cargo de procurador de las misiones y animación del Vicariato de Méndez. Falleció en 1989; y, Silvio Broseghini, ${ }^{18}$ quien se dedicó a profundidad al estudio de la cultura shuar, su temática de interés fue la evangelización pero con un nuevo enfoque de respeto a los valores y costumbres shuar. Trabajó también en el área social, apoyando iniciativas productivas de los shuar. Falleció en el 2003.

Entre los misioneros vivos, destacamos a Siro Pellizzaro, italiano, emprendió el estudio para conocer la cultura shuar y desde su interior tratar de refutar sus "supersticiones" y cambiarlos de mentalidad; pero este conocimiento y los cambios que se produjeron en la época realizaron un viraje radial en su enfoque:

...a los salvajes aún los estoy buscando y creo que nunca los encontraré. Esos que creíamos ignorantes conocían a la perfec-

16 Centro Misional de Investigaciones Científicas. Algunos de sus miembros fueron: Ernesto Álvarez, que llegó a ser Arzobispo de Cuenca y Hernán Crespo que llegó a ocupar el cargo de Director del Museo de Antropología del Banco Central del Ecuador.

17 Su texto principal: Germani Alfredo (Aij'Juank) (1984, p. 9).

18 Su obra principal: Broseghini (1983, pp.10 y ss.). 
ción la selva... por fin descubrí que esos hijos de las tinieblas eran verdaderos hijos de Dios... ${ }^{19}$

Hoy continúa con sus investigaciones; ${ }^{20}$ Juan Shutka ${ }^{21}$ impulsó la creación de la Federación Shuar, organización que se dedica al rescate y promoción de la cultura shuar, aunque inicialmente nació para defender el territorio de los Shuar. También apoyó con el nuevo modelo de Educación Intercultural Bilingüe en los años sesenta; y por último, Juan Bottasso, ${ }^{22}$ sus escritos serán particularmente citados, fue el primero que inició una investigación sistemática y científica sobre el tema que nos ocupa.

\section{Contexto de la comunidad que rodea el internado}

El pueblo shuar (antes de la llegada de los misioneros) vivían en familias ampliadas dispersas en la selva. Tenían esporádicos contactos con otras familias, tan solo para estrechar alianzas matrimoniales o unirse para marchar en contra de enemigos comunes, compromisos que terminaban apenas se cumplían estos propósitos. Vivían enfrentados en luchas fratricidas permanentes, transmitiendo sus costumbres y valores en forma oral y al interior de cada familia. En el caso de la zona que nos ocupa, la situación tenía unas condiciones particulares.

Las familias shuar que habitaban en lo que hoy es Sevilla Don Bosco se encontraban al margen izquierdo del río Upano, pero al frente estaba la población mestiza de Macas, que llevaba décadas si no siglos de asentamiento, rodeada por población

Pellizzaro, Siro, Un misionero se confiesa, II parte "Cambiar para avanzar”, en: Broseghini (1978).

20 Pero la obra de mayor envergadura que se debe a su iniciativa es Mitología shuar, que salió en 12 tomos y constituye uno de los cuerpos mitológicos más completos que exista de un grupo aborigen de América". Bottasso (1982, p. 131).

“...sacerdote checoslovaco, llegó al Ecuador en 1953 y trabajó en Méndez, donde vio las inequidades que enfrentaban los shuar y tomó la decisión de dedicarse a ellos..." (Rubenstein, 2006, p. 39). 
shuar. Quienes han analizado esta realidad sostienen que entre estos dos grupos existieron contactos esporádicos pero sostenidos en el tiempo, en medio de muchas tensiones, apoyos e intercambios comerciales mutuos (Costales y Costales, 1978, pp. 7 y ss.; Carrera, 1987, pp. 12 y ss.; Barrueco, 1959, pp. 9 y ss.). Cuando llegaron los salesianos a esta zona, algunos shuar trabajaban en las propiedades de los mestizos y en alguna media podían comunicarse, además de que muchos macabeos hablaban la lengua jívara pero deformada ${ }^{23}$ habían tenido que aprender para poder comunicarse con los shuar, en este caso ellos eran el grupo minoritario frente a los shuar.

Esta cercanía evidentemente favoreció la entrada de los misioneros, que desde 1929 ya cruzaban el río Upano para visitarlos en la actual población de Sevilla Don Bosco. En Macas ya funcionaba un internado al que frecuentaban shuaras del otro lado del río, los mismos que al concluir la escuela, formaban nuevas familias y se asentaban alrededor de la misión, como se explicará detalladamente en el capítulo II. El promotor de esta obra fue el obispo Domingo Comín, impulsor también de los Internados. ${ }^{24}$ Fueron entonces los internados los que dinamizaron el surgimiento de los poblados, los internados primero y las poblaciones después fueron llamando a los habitantes. Así ganó solidez la obra misionera y civilizadora. En estos nuevos asentamientos poblacionales tenían que practicar las nuevas y

"Tal como habían hecho los misioneros que les habían precedido, ellos comenzaron a aprender el shuar de los Macabeos, hasta darse cuenta que hablaban un dialecto híbrido, deformado y ridículo. A ellos también no les tocó otro remedio que acudir a las fuentes genuinas, con una ventaja: con el sistema de los internados, se volvió el aprendizaje menos costoso... los informantes estaban en casa, eran internos" (Bottasso, 2001, p. 68).

"El internado ha venido a convertirse en el gran secreto para la evangelización y civilización de la raza Shuar. Mons. Comín y los misioneros venerados que conocieron los tiempos difíciles de la primera hora coinciden en esta apreciación: la creación de los internados hace época en la historia de la Misiones Salesianas del Ecuador. Niños de ambos sexos crecen a uno y otro lado de la Misión. Educados para una nueva vida quedan vinculados por el afecto nacido en la vida del internado. Los matrimonios formados con los jóvenes ya crecidos se van estableciendo en los alrededores de cada una de las misiones, sentando los yacimientos de nuevos pueblos..." (Barrueco, 1996, pp. 105 y ss.). 
"buenas costumbres" adquiridas en los internados, ${ }^{25}$ estaban

llamadas a ser el "ejemplo" a seguir por el resto de la población shuar que colindaba el internado.

Un par de generaciones educadas bajo estos principios católicos, provocó el surgimiento de nuevas comunidades cuyos miembros censuraban las antiguas costumbres shuar. Era necesario que este cambio estuviera celosamente acompañada por los misioneros (surgen la figura de los misioneros itinerantes que visitaban a las comunidades), se cuidaban no solo a las familias shuar bautizadas, sino la conformación misma de las nuevas familias que debían recibir, de alguna manera la aprobación del misionero, ${ }^{26}$ lo que antes lo hacían sus padres.

Esta transformación del pueblo shuar se gestó en los internados, ${ }^{27}$ de donde salían hombres con una nueva mentalidad, que organizaron su vida personal y social de distinta manera. Esta era la intensión de los misioneros salesianos y también eran las aspiraciones del contexto nacional. ${ }^{28}$

"...los nuevos hogares cristianos se ganaron la simpatía de los montaraces solitarios. Los hombres jóvenes se comprometieron con una sola mujer. Los viejos polígamos fueron adquiriendo conciencia de culpa. Muchos de ellos plantearon serios problemas al sacerdote que les había señalado nuevos caminos para la familia y el matrimonio. Los más contumaces se alejaron para esconder lo que en el sentir de los integrantes de las nuevas colectividades era ya proceder censurable" (Barrueco, 1996, p. 105).

26 "Los jóvenes educados en la Misión salía del brazo de su esposa para la vivienda de modelo distinto... Los que habían crecido en la selva vinieron también a la Misión. Querían esposas bien vestidas que entendieran de comida y de costura, de mejores lechos, de vajilla nueva y limpia, de razas de animales domésticos... y sobre todo, que formaran de sus hijos hombres distintos de los antiguos" (Barrueco, 1996, p. 106).

27 “...los internados están destinados a aperar esta transformación con la educación de las nuevas generaciones..." (Barrueco, 1996, p. 106).

28 "En la década de 1940, la Iglesia desvió su atención de los adultos hacia los niños, quienes eran llevados a la escuela de la misión. Los efectos de esta estrategia fueron profundos: en primer lugar, las misiones se convirtieron en lugares centrales dentro de la reserva shuar, proveyendo más estructura y sustancia al territorio shuar. Además, la misión socializaba a los niños shuar para que se desempeñen en un nuevo tipo de jerarquía... Pero su conocimiento de, y acceso a, la sociedad Ecuatoriana también les daría ventaja sobre los otros shuar. Educados en lugares centrales dentro del territorio shuar, ellos se convertirían en personas centrales de la sociedad shuar" (Rubenstein, 2006, pp. 33-34). 


\section{"Comunidades" shuar que abarcaba (área de influencia territorial)}

No se podría hablar propiamente de comunidades shuar antes de la llegada de los misioneros al territorio estudiado, ${ }^{29}$ pues los Shuar tenían una estructura social que los antropólogos han denominado familia ampliada:

El ecosistema amazónico no soporta una concentración demográfica excesiva. Los hombres que en él se han establecido, como los shuar, han desarrollado una técnica que les permitió vivir sin alterar el equilibrio biológico y se han dado una organización social que mantiene a la población muy esparcida, es decir, utilizan un tipo de asentamiento que requiere grandes extensiones. Algunos antropólogos han avanzado la hipótesis que el estado de guerra, que tradicionalmente era permanente entre los shuar, no haya sido otra cosa que un instrumento para controlar el número y mantenerlo proporcionado a las reales posibilidades del medio ambiente, (...) ellos además no conocen una organización social más allá de la familia ampliada, que generalmente vive aislada y alejada de otras. (Bottasso, 2011, pp. 23 y ss.)

Estas familias vivían muy distantes unas de otras y muchas veces enfrentados en guerras intratribales. Una de las primeras tareas que realizaron los misioneros fue explorar el terreno y censar a estas familias y sus miembros. ${ }^{30}$

Con estos datos iniciales — recogidos al año siguiente que empezaron a visitar esta zona - los misioneros planificaron la fundación de la misión de Sevilla desde el poblado de Macas:

"...se puede decir antes de la llegada de los misioneros, la población shuar no era como la población actual, eran pocas, puedo decir que aquí en Sevilla Don Bosco no había tanta población, no había comunidades, sino familias, de aquí un día (de camino) una familia, de aquí otro día otra familia, eran familias, entonces más que todo se mantenía ese equilibrio de hombre-naturaleza" (Entrevista a Galo Picham, 2011).

“...del 28 de agosto al 01 de septiembre de 1930, el padre Stahl, el clérigo Ángel Rouby y las hermanas sor María (Troncatti) y sor Dominga (Barale), regresaron a la Banda y recorrieron toda la comarca hasta llegar a Sucúa, realizando un censo minucioso que arrojó el número de 500 habitantes" (Guerriero \& Creamer, 1997, p. 128). 
...a partir del internado de Macas, los misioneros proyectaron

su impacto al otro lado del río Upano, es decir, la actual Sevilla. Los egresados del internado 'no debían volver a su estilo de vida acostumbrado, ni siquiera al mismo lugar geográfico, sino ir formando, poco a poco, una población cristiana alrededor de la iglesia, y emprender una existencia nueva, bajo la mirada paterna, ya severa, ya condescendiente, pero siempre vigilante del misionero...' (Bottasso, 1982, p. 126)

Desde el comienzo esta misión proyectó constituirse en un poblado shuar. ${ }^{31}$ Algunos de los que estudiaron en estos años en el internado de Macas, ${ }^{32}$ luego de contraer matrimonio fueron motivados por los sacerdotes a radicarse en este lugar. ${ }^{33}$ Estos censos entonces les permitían a los misioneros tener una noción de la población con la que trabajarían y para realizar el correspondiente seguimiento de los ya bautizados.

En el documento: "Viaje del P. Pérego a Mangoziza 1959", ${ }^{34}$ se describe un censo realizado en la actual zona de Sevilla por este misionero, en este se constató que la población de los alrededores había crecido considerablemente. ${ }^{35}$ En el año de 1961,

31 "No es simplemente un centro misional más, sino la tentativa de construir una población shuar, según el modelo de los poblados "verdaderos". Nacieron grandes proyectos y esperanzas..." (Bottasso, 1978, pp. 35).

Los jóvenes matrimonios shuar que salían del internado de Macas desde 1933 establecieron nuevas poblaciones al otro lado del río Upano. Este modelo fue establecido para todas las misiones ente los Shuar. En 1944 el internado de Macas se trasladó a Sevilla Don Bosco (eran 56 varones), de aquí en adelante ésta institución creció vertiginosamente, para la década de los 60, sobrepasaban el número de 400 los internos (AHMS, folio II. Sv).

33 "Siguiendo la política educacional de entonces se formaron los primeros poblados con familias salidas del internado, en zonas próximas a la misión. Los primeros ensayos en este estilo fueron los de Sevilla, Bomboiza y Asunción. La intensión era mantenerlos fuera del ambiente de la selva para que no revivieran las costumbres de los mayores" (Barrueco, 1996, p. 108).

34 Este informe del padre Pérego fue publicado como un Apéndice en: Ochoa y Sierra (1976, p. 85). El original se encuentra en el AHMS.

35 "Siendo responsable de la Misión de Sevilla don Bosco, quería formarme una idea exacta tanto de la población shuar como de su ubicación en toda la región a mi confiada, y basado en este conocimiento, formar pequeños subcentros misionales con capilla adecuada bajo la inmediata responsabilidad de un catequista seleccionado entre los shuar educados en la Misión. EI P. Rafael Clemente, infatigable trabajador entre los trescientos internos del centro y encargado de los shuar paganos que viven fuera de Sevilla, ya había completado el censo en la región del Yuquipa, afluente del 
este religioso bautizó a 69 niños shuar, 75 recibieron la primera comunión y construyó un comedor para 150 shuar internos. En la misión trabajaron en estas fechas, el P. Domingo Pérego (Director), P. Rafael Clemente (Consejero) y el Sr. Marcos Molina (acólito) (AHMS, Sv). A partir de la presencia de los salesianos en Sevilla, el número de habitantes creció, debido a dos razones. Por un lado, la población shuar que vivía dispersa, empezó a aglutinarse alrededor de la misión, los padres acostumbraban a visitar constantemente a sus hijos en los internados y la misión se convertía en un centro de acogida, de intercambio y comercialización. Por otro lado, fue una estrategia de los misioneros ${ }^{36}$ el proporcionarles terrenos y ayudarlos a construir las viviendas ${ }^{37}$ a los matrimonios que salían de los internados. ${ }^{38} \mathrm{El}$ objetivo fue garantizar el seguimiento espiritual de estas familias. ${ }^{39}$

En estos años los misioneros (al igual que los curas párrocos en otros contextos), se encargaban de muchas actividades: vías de comunicación, construcción de viviendas, educación, salud, etc., de las que no siempre estaban a cargo directo, pero en las cuales

Upano a $3 \mathrm{~km}$. La población asciende a 913 personas, en su totalidad paganos, sin contar con las 84 familias que forman la población urbana de Sevilla" (AHMS, Folio III. Sv).

"Toda su historia demuestra, al menos hasta los años cincuenta, una estrecha conexión de la acción de catequesis con la promoción del "progreso" y la "civilización" en las tierras amazónicas, y en especial con la colonización de aquellas tierras..." (Colajanni, 2008).

37 "El Centro Urbano que se ha ido formando con las familias cristianas salidas cada año de la Misión, cuenta con unas 600 almas, agrupadas en unas 70 casas con sus respectivas familias, casas construidas, en su mayoría con muy buena madera y siguiendo un preestablecido plan regulador, con sus avenidas, sus plazas y jardines y con una magnífica pista de aterrizaje, en construcción" (Boletín Salesiano del Ecuador, junio 1958, p. 9).

"...cuando los jóvenes y las muchachas de Macas, internados en los colegios habían llegado a la edad necesaria, los hacía unir en matrimonio. Luego les asignó a cada cual su casa, con huerto, en Sevilla Don Bosco, y los unió así en colonia, en la que edificó la iglesia y colocó a los Misioneros. Más tarde, ese núcleo formará muchos otros y la civilización cristiana romperá por completo el misterio de la selva, creando para siempre una generación nueva" (Guerriero, 1944, pp. 40-41).

"Atención al desarrollo de la población de Sevilla, mantenerlos unidos y afectuosos a la Misión interesándose en sus problemas y siguiendo una vida de buenos cristianos", firma el padre Felipe Palomino (Visitador Canónico), marzo de 1953 (AHMS, folio III, Sv). 
evidentemente se involucraron. ${ }^{40}$ Esta especie de delegación de las responsabilidades propias del Estado, fueron asumidas por el Gobierno a mediados del siglo XX, cuando se establecieron algunas instituciones gubernamentales en esta parroquia. ${ }^{41}$ Se dio por tanto una transformación general en el sistema de vida tradicional de los shuar, había llegado a ellos la "civilización".

Este considerable aumento demográfico de la población shuar en Sevilla ${ }^{42}$ impulsó a los misioneros a fundar y establecer otros "centros" alrededor del área de influencia de la Misión. ${ }^{43}$ Inicialmente estos centros nacieron de la misma estructura de familias ampliadas que se juntaron en un sitio y allí el misionero les ayudó a construir una capilla, una escuela, una cancha y eligió a colaboradores para las celebraciones litúrgicas de entre los Shuar más destacados, que casi siempre eran los que habían estudiado en el internado. ${ }^{44}$ Unos años más tarde estos colabo-

"las circunstancias peculiares de estos jóvenes centros de vida, exigen que el Padre Misionero, a más de desempeñarse dentro de los espiritual, asuma también una vigilancia directa o indirecta sobre aspectos que en nuestro ambiente son de pertenencia de la Autoridad Civil. ¡Qué cosa mejor en efecto, que el paso de la absoluta libertad a una disciplina de un pueblo civilizado se realice por medio de quien su mismo estado le inclina más al perdón que a la severidad!" (Revista Don Bosco en el Ecuador, Mayo-junio, 1950, p. 287).

41 "...los habitantes de la nueva parroquia de Sevilla Don Bosco son en su mayoría casi absolutamente indígenas de raza "Shuara" (Jívara) y, contando con los anejos de la parroquia, llegan a unos 1.900. La población cuenta con el servicio nocturno de luz eléctrica, con teléfono directo a Macas, con una estación de radio, con un transporte para uso agrícola. Hay cinco tiendas (pequeños almacenes), amén de sastrerías, peluquerías, herrerías, mecánica: atendido todo esto por Jivaritos educados en la Misión" (Boletín Salesiano, junio 1958, p. 9).

"Estas misiones se sintieron impotentes para absorber a su alrededor a todas las nuevas familias que se iban formando y tuvieron que optar por fundar, dentro del área de su dependencia, otros centros de tipo rural y de dimensiones más modestas, respetando siempre lo que para los shuaras constituye la base para la formación de todo núcleo o agrupación: la relación familiar de parentesco. Con esto se les ofreció una alternativa - acorde con la educación recibida - a su sistema primitivo de viviendas aisladas y dispersas en la selva. Es precisamente lo que se llamaría: centros" (Carollo, 1987, p. 147).

43 "Hasta la década de los 50 los valles del Upano, del Paute, del alto Zamora y del Bonboiza se llenaban de caseríos. Y en todos ellos hace presencia el misionero, en el templo, en la escuela, en las calles, y en los hogares. El misionero es el amigo de todos, el orientador de la vida ciudadana; el hombre orquesta requerido y valorado en todas partes" (Barrueco, 1996, p. 109).

44 "Poco a poco entró la idea de la Iglesia autóctona como signo local de la Iglesia universal. Era necesario ahora escoger en cada iglesia local alguien que representara al Buen 
radores se convirtieron en síndicos ${ }^{45}$ de los centros con muchas más responsabilidades que las espirituales.

Se evidencia este crecimiento demográfico en la fundación de nuevos centros alrededor de la misión (como también la construcción de vías ${ }^{46}$ y obras de infraestructura ${ }^{47}$ ), cuyos nombres obedecían a la toponimiade los ríos, montañas o el nombre de algún misionero, ${ }^{48}$ como es el caso del centro Ángel Rouby, de numerosa población y ubicado geográficamente muy cerca de la cabecera parroquial de Sevilla. Algunos de los centros que se formaron entre las décadas de 1950 y 1970 fueron: Tucupi, Wapú, Wapú Sur, San Ramón, Uunt Wichim, Uchich Wichim, Mutins, Santa Rosa, Uyuntz, Suntsunts, Pikiur, Untsuri Entsa, Buena Esperanza, Yurank, Kusuim, San Juan, Las Cascadas, Kenkuim, Las Palmeras, Ángel Rouby, Himpis, Shimpis, Kiluba, entre otros. En 1966, se fundaron los centros: Wichim', San Luis, Guadalupe y Angel Rouby a orillas del Yukias, al este de Sevilla (Guerriero \& Creamer, 1997, p. 141).

Pastor en las reuniones dominicales para que explicara la Palabra de Dios y guiara la oración. Yo no podía ser un Pastor porque no soy shuar y no comprendo a fundo su cultura... Para esto debí aprender sobre todo el idioma shuar. Escogí un Pastor y un ayudante en cada comunidad, entre las personas que demostraban más interés religioso y comencé a reunirlos en la misión cada mes. En estas reuniones dialogábamos sobre la cultura shuar, pues la mayoría de los Pastores era ya adultos. También hablábamos naturalmente sobre el Evangelio de Jesús..." (Pellizzaro, Siro, Un misionero se confiesa, II parte "Cambiar para avanzar", en: Broseghini, 1978, pp. 33-34).

Personas delegadas de los misioneros que estaban encargadas de administrar el centro. Precedían las celebraciones religiosas cuando los religiosos no podían hacerlo, se encargaban de organizar a la comunidad para mingas de limpieza de caminos, construcción de viviendas; y muchas veces cumplían también con tareas educativas en las primeras escuelas de estos centros.

46 "En noviembre de 1962 se traza el camino que va a Yukias, atravesando las propiedades de la misión, se marcan los linderos norte-sur y se solucionan conflictos vecinales. Según el censo de este año, la parroquia tenía 280 familias y 1780 habitantes" (AHMS, Sv).

"En febrero (1966) llega un ingeniero del Cuerpo de paz para levantar los planos de la pista y el 09 de agosto aterriza la primera avioneta para servir a la misión y la región" (Guerriero \& Creamer, 1997).

"Si atendemos a la toponimia, destaca el hecho que los salesianos establecieron un criterio principalmente geográfico para dar nombre a los centros que fundaban, los cuales recibieron el nombre de los ríos o de los valles en que se encontraban situados, siguiendo la costumbre shuar" (Esvertit Cobes, 2012). 
En la década de 1960, los salesianos replantearon los cri-

terios iniciales de concentrar a la población. ${ }^{49}$ Se dieron cuenta que estas nuevas poblaciones no debían abandonar sus tierras, allí estaba el sustento de su alimentación y se intentó evitar de alguna manera la "urbanización" de estos poblados. La dinámica de surgimiento de los centros alrededor de las misiones, era un hecho que muy difícilmente los misioneros pudieron regular en las siguientes décadas.

\section{Desde la perspectiva de los internos}

Se extrae algunas ideas de los escritos de los misioneros que permiten descubrir lo que los shuar experimentaron al momento de entrar en contacto con los religiosos. Otra fuente de documentación son los escritos que los mismos shuar dejaron una vez que concluyeron sus estudios secundarios y superiores. Y finalmente cito las entrevistas que he recogido en los últimos años.

La visión teológica católica que no considera la naturaleza humana "totalmente corrompida", hizo a los misioneros católicos más tolerantes que los protestantes con respecto a las costumbres de los pueblos indígenas. En esta línea, los misioneros salesianos que trabajaron con los shuar, aunque inicialmente no valoraron la cultura de este pueblo, sí intentaron rescatar algunos rasgos de sus valores culturales, ${ }^{50}$ la intensión fue de alguna manera prepararles para que en un futuro cercano $\mathrm{pu}$ -

"En 1961 los superiores de la recién constituida inspectoría (provincia) de Cuenca examinaron la situación de las misiones y admitieron que había que modificar el proyecto de formar los poblados Shuar. Dicen, al respecto, en el documento final (No. 6): Estudiando con detalle este importante problema se dedujo ser preferible vivan algo diseminados, a no larga distancia de la misión, a fin de que dispongan de terrenos convenientes para su subsistencia. Ayudémosle a construir sus casitas, con acierto, gusto y holgura", en: Bottasso (1982, p. 128).

50 “...Eduquémoslo también al espíritu de cuerpo y hagámosles comprender que no tienen ningún motivo para avergonzarse de ser jívaros; sepamos aprovechar su espíritu innato de orgullo, para educarlos al sentido de la dignidad cristiana y humana... Nuestros internos no deben formarse la idea de que son peones..." (Circular del padre Juan Vigna del 03/X/1944, AHMS / VII, V). 
dieran convivir con otros pueblos que llegaron masivamente a sus territorios. ${ }^{51}$

Ante esa pretensión surgen dos interrogantes: ¿cómo respondió el pueblo shuar? y ¿cómo valoró ese propósito? Existen al menos dos tendencias marcadas que se dieron entre los shuar,

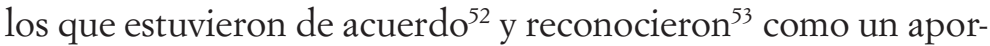
te ${ }^{54}$ para su pueblo la llegada de los religiosos y quiénes fueron completamente críticos de ese proyecto por considerarlo perjudicial a la estructura social, ${ }^{55}$ la pérdida de los valores culturales originarios, ${ }^{56}$ y el consecuente proceso de aculturación. ${ }^{57}$

51 “... la mayoría de los líderes shuar de las nuevas estructuras y organizaciones (obviamente los líderes tradicionales están fuera de discusión), han crecido en ambientes mixtos, adquiriendo, al lado de los compañeros blancos, sus medios expresivos, sus habilidades, astucias, malicias que les permiten entregarse, con cierta igualdad de herramientas, a la defensa de los derechos de grupo... Después de un contacto continuado con la cultura mestiza que les ha permitido ir más allá de las apariencias y después de haber experimentado la imposibilidad de una toral asimilación de ella, muchos Shuar están hoy en condiciones de medir la importancia de recuperar su tradición y sus valores, por lo menos en parte" (Bottasso, 2011, pp. 45-50).

"Sin la misión no hubiéramos sido un pueblo civilizado y tampoco podríamos progresar solos (Juana Wampank, fue interna)" (Ochoa \& Sierra, 1976).

53 "Yo para decir la verdad, yo soy serio en las cosas, a mi me gusta mantener responsabilidad, yo al momento no he visto cosas negativas en los sacerdotes, ni tampoco yo soy contrario a los sacerdotes en cuanto por ello me eduqué, ellos me formaron, gracias a Dios por ello tengo mis generaciones, una que trabaja en Guayaquil, es bachiller se gradó en San Juan Bosco, tengo otro hijo que dios mediante en el mes de julio se va a incorporar..." (Entrevista a Miguel Chuint, Sevilla, 2011).

54 "Por los misioneros ahora estamos bien y respetan nuestros derechos (Mónica Ayuí, casada se educó en la Misión)" (Ochoa \& Sierra, 1976, p. 46).

55 "La aparición de la Misión Salesiana, nos trajo necesidades que antes no teníamos; desde el aspecto físico la Misión es una gran casa con todas las comodidades, el pueblo se ve pobre; adentro se come bien, en el pueblo hay gente que no se alimenta bien, cando apareció la Misión ya comenzaron las diferencias entre los superiores padres y los inferiores que éramos los del pueblo (R. Tankamash)" (Ochoa \& Sierra, 1976, p. 46).

"Hemos perdido nuestra cultura, porque llegaron los misioneros que no fueron aptos para guiar al pueblo shuar, todo metían en el campo religioso ( $R$. Tankamash, graduado en el Normal Don Bosco, estudia leyes en al U. Católica, casado con tres hijos)" (Ochoa \& Sierra, 1976, p. 46).

"La parte negativa es que nos han quitado nuestros valores en primer lugar, nos han cerrado nuestros conocimientos, nos apoderaron, ellos nos quitaron lo que era de nosotros y nos transmitieron lo que de ellos y lo de nosotros se ha quedado atrás eso es lo peor error que han cometido ellos. Si es que nos hubieran empatado como hoy en la religión como nos dicen hubiésemos caminado, por lo que ello son dieron el acomplejismo y la aculturación por eso es que hoy para empatar eso está difícil..." (Entrevista a Miguel Ankuash, 2010). 
Shuar", sus dirigentes parten por justificar la validez de su cultura, ${ }^{58}$ aquellos valores no vistos ni valorados en los primeros tiempos, pero que estuvieron allí. ${ }^{59}$ José Jintiach, en su tesis de licenciatura resume de algún modo su experiencia y visión del internado ${ }^{60}$ y los métodos que allí se utilizaban. ${ }^{61}$

58 "Desde las primeras expediciones españolas desde 1540, con Rodrigo Núñez de Bonilla, Hernando de Benavente, Gil Ramírez Dávalos y otros, el Pueblo Shuar se presenta como poseedor de una cultura de selva, con idioma, costumbres, estructuras e idiosincrasia propias. Se cree que el pueblo shuar tiene su marco referencial en la cultura Arawak, ya que ambas culturas e idiomas tienen sus semejanzas (Thoret, p.4)", (Federación Shuar, 1977).

59 "La religión del hombre shuar se presenta rica en mitos, plegarias, cantos y tradiciones; pero relativamente austera en ritos exteriores, culturales. El hombre shuar vive en comunión con un universo vivo, en comunión y contacto permanente con sus antepasados, divinidades, arquetipos. Religión de tipo místico, imbuida de temor, magia y ritos "fármaco-mistéricos". La mitología es abundante. Sus mitos con cosmogónicos y cosmológicos, filosóficos, religiosos, morales y estratégicos (Pellizzaro, 1968). Constituyen la superestructura arquetípica a la cual el shuar debe adaptar su vida. El mito le señala sus obligaciones, costumbres, tabúes y hasta el detalle de su quehacer diario. La caza, la pesca, artesanías, la guerra, todas las principales actividades de la vida y muerte de este hombre están señaladas en la mitología" (Federación de Centros Shuar, 1977, p. 12 y ss.).

"El internado, obviamente tiene sus inconvenientes, pero tampoco se puede negar las ventajas que ha ofrecido al grupo en un momento en que este debe afrontar la incógnita de un cambio rapidísimo. Gracias a los internados, por ejemplo, en años pasados la niñez shuar ha logrado un alto porcentaje de alfabetización. En la década del sesenta el número de internos en las solas misiones salesianas se acercaba a 2000 cada año, entre chicos y chicas (sobre una población de 20000). Hoy, con el sistema de Escuelas Radiofónicas, organizado por la Federación de Centros Shuar, han casi desaparecido los internos de primaria, pero el internado sigue siendo algo inevitable para la mayoría de los jóvenes que quieren estudiar (La Federación y las misiones están buscando maneras y técnicas de capacitación que no alejen tampoco a ellos del ambiente natural)" (Jintiach', 1976, p. 5).

61 "... el aprendizaje resultaba deficiente, sin el fruto intelectual que se esperaba y sin un mejoramiento social. En estas circunstancias, se siguió más bien el método hace mucho superado: "La letra con sangre entra". El fruto de esta formación como podemos esperar, fue de una desproporcionada ruptura ente la ciencia y a vida; entre lo aprendido y lo que se tenía que aprender. En lugar de formar hombres socialmente educados, capaces de tomar la vida por sus riendas, se crearon hombres tímidos, incapaces de tomar decisiones personales. Los primeros misioneros llegaron también con métodos rígidos, nuevos, ciertamente, pero autoritarios, con una disciplina férrea, impuesta con mucha fuerza. Ya podemos imaginarnos lo que sucedía en el interior de personas acostumbradas a una libertad sin medida... Tenemos que anotar, por otra parte, que en ciertos internados, debido a esta falta de adaptación educativa, y como consecuencia de un régimen de autoritarismo, de no valoración de la raza y de sus costumbres y de la persona como tal, se creó un clima de rebelión entre los estudiantes" (Jintiach', 1976, p. 45). 
Evidentemente, el trabajo con un pueblo con unas costumbres y cultura distintas, dificultó las relaciones entre los misioneros y los internos. Estos impases, cuando no fueron hábilmente manejados por los primeros, causaron resistencia y resentimientos en la población que pasó por los internados. ${ }^{62}$ Después de los fracasos vividos por los misioneros se trató de mejorar el sistema educativo. Los resultados que se obtuvieron con esta clase de nuevas experiencias fueron reconocidos como positivos por los shuar, ${ }^{63}$ no así el tema de la disciplina dentro de los internados ${ }^{64}$.

Algunos párrafos de la novela Natar de Ansuvi refieren el aspecto educativo, el modelo de enseñanza que era completamente nuevo y contrario ${ }^{65}$ al modelo que habían seguido al interior de sus familias; aunque se trate de una obra literaria es-

“...para muchos, la rebelión fue causa de problemas psíquicos ya que no se comprendía la dimensión de sus posiciones y de sus rebeldías. Esto trajo como consecuencia el que en muchos shuar se despertara un marcado sentido de desconfianza, de odio y de desprecio hacia los valores impositivos, no madurados ni hechos para un ambiente culturalmente distinto. Esto, trajo como consecuencia las fugas de los internados" (Jintiach', 1976, p. 45).

63 "En educación, bueno nos enseñaron por lo menos a representar lo que solamente hablábamos, ahora podemos imprimir, podemos grabar, escribir lo que tenemos como conocimiento no, eso es positivo..." (Entrevista a Galo Picham, 2011).

"Muchas veces esa actitud demasiado "policial" de los misioneros provocaba que las nuevas parejas se rompían fácilmente olvidándose de las buenas enseñanzas recibidas en la Misión, para perderse, mezclándose en la sociedad de sus antepasados. Con el pasar del tiempo la pareja era considerada como una de las ignorantes. "Tenía razón para volver al estado de sus antepasados, para seguir las costumbres de sus padres ya que en el internado no se les había dado la preparación adecuada. En efecto, es precisamente en el tiempo del internado, cuando el joven necesitaba prepararse para la vida, tener relaciones sociales, especialmente con las chicas. También debía conocer quién sería más tarde su esposa... Se sentían siempre perseguidos en su conciencia de que todo lo que hacían era pecado, y es por eso que los superiores decían que todo lo que no hacían de acuerdo a sus exigencias era pecado" (Jintiach', 1976, p. 49).

"El primer contraste fue el basamento mismo de la educación... No podía entonces - por la corta edad comprender ni explicarme el por qué de aquella desconfianza y aversión hacia la escuela, compañeras y profesoras que me tenían amordazada desde el comienzo de mi vida escolar... ¡Mamá me enseñaba para la vida... la maestra para el examen! Junto al principal de los postes que sostienen la cumbrera, en el centro de la casa, hay un tronco de cedro pulido con esmero... Sitio y asiento son distinción personal e inalienable del jefe de la casa (del úunt), que en él se sienta con aplomo y majestad de rey... Sentados sobre los talones los hijos escuchan todos los días, por lección las enseñanzas de los mayores" (Ansuvi, "Nantar", Editorial Arquidiocesana, Guayaquil, 1955). 
crita para este propósito, podemos rescatar algunos rasgos del

cambio cultural vivido por los Shuar, muchos de los cuales lo percibieron como una experiencia muy dolorosa. ${ }^{66}$

Se evidencian que fueron años de profundos cambios y transformaciones para este pueblo, pero con la llegada de esta institución religiosa (1943) ciertamente estos procesos se acentuaron de una manera más rápida y generalizada. ${ }^{67}$ Estas transformaciones se evidenciaron más en los roles que cada miembro de la familia debía cumplir: el conocimiento sobre la caza, la guerra, la mitología o las tradiciones como el hecho de quién decidía con quién casarse eran los padres ${ }^{68}$ o el brujo, pero no una persona externa ${ }^{69}$ al grupo. ${ }^{70}$

La transformación cultural que vivió el pueblo shuar de una manera acentuada a mediados del siglo XX tiene diferentes lecturas evidenciadas en los testimonios de quienes vivieron esta experiencia. Como se ha anotado también, las políticas y acciones de los misioneros varió con los años, de un postura

66 "Mandamos a nuestros hijos a la escuela y aprendieron a decir que los papás somos salvajes, que somos criminales, que somos vagos, que nuestro idioma es un idioma de perros, que nuestros cuerpos son feos, y... tantas cosas más" (Chicham, Órgano Oficial de la Federación de Centros Shuar (Bilingüe), Sucúa, 1974).

67 "En el shuar la influencia de los misioneros han sido equivocada. El misionero ha dado la vida por el shuar, sin embargo la forma cómo entró fue lo equivocado porque desde un principio se les dijo: lo suyo es malo, lo nuestro es bueno, su moralidad es mala, la nuestra buena, de esta forma se fue arrasando culturalmente a todo el pueblo (José Arnalot)" (Ochoa \& Sierra, 1976, p. 45).

68 "A los hijos varones se encargaba el papá, a las hijas mujeres se encargaba la mamá de adiestrarlos, de instruirlos en conocimiento y lógicamente había unos cánticos de súplica, para la cacería había los cánticos de súplica llamados anent para la caza, para la huerta, había los anet para la súplica en huerta, entonces la mamacita les enseñaba, a veces les cantaba así debes decir..." (Entrevista a Galo Picham, 2011).

69 "En ese momento era ya el sacerdote él era el que decía que esto es así y eso teníamos que cumplir nosotros o sea ya no la realidad de nosotros sino la realidad de ellos, al antojo de ellos nosotros teníamos que cumplir todo o sea lo que nos transmitían o sea como tenemos que también en el matrimonio el sacerdote decía así tiene que vivir así tiene que hacer, en el trabajo también decía así tienen que hacer y el orden y la disciplina todo lo que ellos dicen nosotros teníamos que obedecer ya no nosotros ya no teníamos ni valor de rechazar lo que ellos nos decían..." (Entrevista a Miguel Ankuash, 2010).

70 "Los misioneros robaban a los niños de sus casas, les quitaban los hijos a los padres, les internaban en las misiones y nos quietaban la autoridad y educación de nuestros hijos (Domingo Pitru, adulto, casado, Presidente de la Asociación Local de centro Shuar)" (Ochoa \& Sierra, 1976, p. 47). 
inicial de buscar suprimir los valores y tradiciones ancestrales por considerarlas "reñidas" con la moral católica se pasó a un reconocimiento y valoración de la cultura de este pueblo. Este cambio de postura de los religiosos me parece que no ha sido entendido, ni asimilado por las generaciones que pasaron por el internado, que hoy sienten confusión y desconcierto. ${ }^{71}$

\section{Conclusiones}

¿Cuáles fueron los alcances de la actividad evangelizadora emprendida por los misioneros salesianos al tratar de cristianizar al pueblo shuar? ¿Cuál fue el grado de participación de los shuar en el proceso de acelerada transformación cultural que vivió este pueblo a mediados del siglo XX?

En primer lugar, voy a considerar que una las críticas más frecuentes a la actividad misionera salesiana es la de haber destruido la cultura shuar con el afán de imponer modelos occidentales. Evidentemente los primeros misioneros actuaron de acuerdo a la "mentalidad de la época" se consideraron llamados a "cristianizar y civilizar" (con todos los medios a su alcance $)^{72}$ con el fin de contrarrestar los "males"73 que habían encontrado en esta cultura. Su actividad entre los shuar fue, desde sus comienzos, definida como el "más difícil y contrastado campo de acción misionera” (Colajanni, 2008, p. 149) caracterizada por un fuerte componente de acción social y sostenida por un método pedagógico flexible y pragmático.

71 "En términos religiosos no sé, yo digo actualmente el pueblo está en crisis porque los mismos religiosos que al principio nos dijeron que vinieron trayendo si es posible el mensaje de Cristo, a predicar el evangelio, ya no predican el evangelio pues, tratan de adaptar la realidad del pueblo shuar, entonces nos dicen que Arutam es Dios, que Jesucristo es Etsa, que la Virgen María es Nunkui y una serie de cosas... En el Internado nos hablaban de Dios puro no... Entonces ahorita nos dicen, no se pues cual inclusive nos han dicho que existe una especie de pastoral, hay una doble pastoral, pastoral de colonos y pastoral de shuar. Que el Dios que predican a los colonos, no es Dios del shuar, que el Dios del Shuar no es el Dios de los colonos, entonces bueno qué mismo estamos..." (Entrevista a Galo Picham, 2011).

Circular de Monseñor Domingo Comín, 03/X/1925. AHMS / VII, Cm.

73 Al principio los misioneros buscaron la manera de frenar las ininterrumpidas venganzas que iba en contra de la "moral cristiana" y amenazaba con aniquilar al grupo. 
El binomio evangelizar/civilizar estuvo presente en su acción, y aunque reconocieron su rol de intermediarios (de los "beneficios" de la cultura occidental), que le permitió ser aceptados y hasta pudo establecer una situación de reciprocidad con el grupo; esta posición no les satisfacía, porque el misionero veía "frustrados sus intentos de cristianización" (Broseghini, 1983 , p. 92). Como la mayoría provenía del extranjero (sobre todo Italia), apenas tenían un conocimiento de la realidad del país y les tocó rápidamente incorporarse al trabajo de la misión.

Fue entonces que surgieron los Internados, los mismos que se consolidaron y fortalecieron a mediados del siglo XX, como el "instrumento" que les permitió a los salesianos realizar el trabajo que por más de tres décadas lo habían buscado: cristianizar al pueblo shuar en los principios católicos y de esta manera extender la "civilización" ecuatoriana a la región Amazónica, facilitando al mismo tiempo el ingreso y ocupación de colonos $^{74}$ a estos territorios (consideraban que los shuar cambiarían siguiendo el ejemplo de vida de "pueblos civilizados") y el posterior asentamiento de las instituciones estatales.

Las misiones se convirtieron en lugares centrales de las relaciones misioneros-shuar, "nódulos esenciales de acceso a los bienes manufacturados".$^{75}$ Los misioneros unieron el poder espiritual y material demostrando su superioridad a través del control de los bienes del "mundo occidental". A través de los niños/niñas educados en los internados se produjo una desestructuración de las relaciones de parentesco y poder de la cultura tradicional, y se produjo una resignificación de un "mundo" al cual los shuar adultos deseaban tener acceso, es por ello aceptaron enviar a sus hijos al internado para que aprendan el castellano y pudieran ser intermediaros entre ellos y los ecuatotrales, dando así una barrera inquebrantable al saber nacional. Por todo lo cual se demuestra que la cruz del misionero es el mejor instrumento de colonización y de progreso" (Guerriero, 1944, p. 38). Este texto otros lo atribuyen a Elías Brito, AHMS, Quito. 
rianos, y de esta manera quedaron incorporados a la lógica del mercado capitalista (Münzel \& Kroeger, 1981).

Por la manera cómo se transmitió la doctrina católica (solo se transfirió conocimientos para que las familias vivan "cristianamente" sin comprender del todo la nueva religión), dejó dudas de la eficacia de su mensaje. Es por ello, que los religiosos (desde la década del 60 y con empuje del Concilio Vaticano II) cambiaron de mentalidad e incorporaron a su misión conocimientos de las ciencias antropológicas, sociológicas y lingüísticas. Se dio una evolución hacia el respeto de las culturas autóctonas. ${ }^{76}$ No se puede desconocer los esfuerzos que estos desplegaron para "conservar y recuperar" los valores culturales del pueblo shuar en las dos últimas décadas de la presente investigación. Desde 1968, a consecuencia de los activos llamados de atención de la Iglesia oficial (a través de sus documentos: Melgar 1968, Iquitos 1971, Asunción 1972), existió voluntad en los misioneros de cambiar de rumbo. Pero las presiones conservadoras de algunos elementos locales no permitieron el completo desarrollo de una nueva pastoral (pastoral shuar) (Germani, 1977).

Parece ser que este segundo mensaje no llegó a la mayoría de la población, o llegó mal porque el actual panorama de la evangelización, por decir lo menos, es desconcertante y al mismo tiempo desafiante para la nueva generación de misioneros, esta vez ecuatorianos.

En segundo lugar, la investigación evidencia que de alguna manera el Estado ecuatoriano (al encargar en 1893 el Vicariato de Méndez y Gualaquiza) delegó a la Congregación Salesiana la conversión de los Shuar, tanto al catolicismo como a la ciudadanía; por lo tanto, tuvo que contar con los salesianos e indirectamente con los mismos shuar. Se trata entonces de un proceso complejo, a través del cual se construyó la identidad cultural de los shuar de hoy, uno de los pueblos más estudiados de la región 
amazónica, y uno de los más representativos de Ecuador, en términos políticos y por la cantidad de su población.

Esta transformación (de los antiguos “jíbaros” en los shuar contemporáneos) resultó no solo de la actuación de los misioneros, sino de una cooperación, muy variable a través de los años, entre estos y los shuar (apareciendo en un momento dado un tercer grupo: los colonos). Es un hecho que un número creciente de shuar, como consecuencia de su preparación en los internados, llegó a alcanzar un nivel de conocimientos que le permitió interactuar con el "nuevo mundo" y al mismo tiempo construir "rasgos identitarios y culturales" bastante distintos o hasta divergentes de los deseados por los misioneros. Por lo tanto, las interacciones y relaciones que se construyeron y se dieron entre los misioneros y los shuar fueron múltiples y muy diferenciadas; construyeron en conjunto una historia de más de medio siglo de acercamientos, tensiones, desconfianzas y colaboraciones (Gnerre, 2012).

Los Shuar a lo largo de su relación con los misioneros supieron plantear sus demandas de manera implícita o explícita. A los misioneros les tocó muchas veces negociar estas exigencias que se volvieron más fuertes cuando se creó la Federación de Centros Shuar y los shuar decidieron tomar un camino de desarrollo independiente. ${ }^{77}$ Esto se evidenció también con el surgimiento de los primeros dirigentes shuar y su capacidad de liderazgo, que imitando una especie de capacidad innata que tenían los misioneros para articular amplios sectores sociales y económicos en pos de sus objetivos, estos también aprendieron a moverse en distintos escenarios a la hora de buscar beneficios para su gente y su organización.

Algunos de los frentes de actuación de los misioneros y shuar fueron: la defensa de las tierras, la constitución de los Centros, la creación de la Federación Shuar, introducción de nuevas prácticas agrícolas y ganaderas, la institución de una radioemiso-

77 "En un sincero esfuerzo de proteger a los shuar, los misioneros se hicieron cargo de las reservaciones temporarias hasta su "civilización", es decir que cuando ellos parecieron estar suficientemente aculturados, los dejaron a la merced del colono" (Germani 1977, pp. 19-20). 
ra, el sistema de educación bilingüe intercultural, la construcción de obras civiles como caminos, puentes, escuelas, centros de salud, etc. Todo esto fue posible gracias a formas distintas de colaboración y cooperación conjunta. Todos estos proyectos contribuyeron, cada uno en formas y medidas distintas, "a equipar a los shuar con los instrumentos para su continuidad histórica" (Gnerre, 2012, p. 580). Caso contrario, sin el aporte y la actuación misionera salesiana (cambiante y contradictoria a lo largo de su presencia entre los shuar), estos muy probablemente no hubieran podido fortalecerse, en términos étnicos y demográficos, y como pasó con otros pueblos amazónicos, hubieran podido hasta desaparecido en ambos sentidos. De no haberse creado la "Federación de Centros Shuar" (iniciativa de un misionero) pero con la inmediata participación de la comunidad, el grupo habría sufrido una desmembración territorial: tanto más que el shuar "aculturado" no es ya el "orgulloso y combativo hijo de la selva", sino un "indio manso" caído en la pobreza y sumido en las necesidades más urgentes: comida, vestido, medicinas..., las que lo empujaron al círculo vicioso de ventas de la tierra.

En tercer lugar, señalar que los dirigentes shuar surgen del accionar misionero, que siguió la misma línea del Estado (con el cual celebró contratos legales). Esta estaba dirigida a la "culturización" del shuar, es decir, a su aculturación para que comprendiera el idioma y la vida del "blanco" y así no diera problemas a las autoridades y a los organismos oficiales. La política estatal de "integración=asimilación" fue seguida por los misioneros, que intentaron incluir la "evangelización” en este proceso (Germani, 1977, pp. 19-20). Por eso se cayó en el error de identificar "cristianismo" con religión del hombre "blanco" y moral cristiana con la del colono. El resultado (salvo contadas excepciones) fue un cristianismo superficial que desaparecía en cuento el shuar volvía a lo íntimo de su familia; pero esta vez, no encontrando ya en ella (por la aculturación) mecanismos de control religioso y moral tradicional, solo dejaba lugar a un ateísmo práctico y a un relajamiento moral.

Otro factor que determinó el tipo de liderazgo emergido entre los Shuar fue el complejo de inferioridad a consecuencia 
de la educación de escuelas e internados misionales (y públicas ocasionalmente) que producían individuos deseosos de salir de su tierra, vergonzosos de su cultura, prontos a renegar de sus mitos y creencias, y en ocasiones buscaban conservar comportamientos netamente derivados de ellos (el aumento sensible de brujos fue directamente proporcional a la aculturación). ${ }^{78}$

La presencia de la misión salesiana tuvo mucho que ver en esta transformación del grupo shuar. La culpa de que hayan perdido muchos de los valores culturales quizá no se puede atribuir exclusivamente a los misioneros como personas, sino a la formación que ellos a su vez recibieron para poder trasmitir el mensaje; antepusieron a todo una finalidad evangélica y religiosa olvidándose de valorar y comprender a profundidad la realidad que los rodeaba.

No estoy convencido si asistimos a un verdadero proceso de revalorización cultural. Al parecer estas afirmaciones optimistas se quedaron a nivel de algunos dirigentes shuar que provocó y levantó mucha expectativa en finales del siglo XX, pero no llegó a la población entera, quien aún hoy siguen teniendo tensión y confusión a la hora de enfrentar los cambios culturales que provocó la presencia de las misiones salesianas en su región y que modificó radicalmente su forma de vida ancestral.

\section{Bibliografía}

Barrueco, D. (1959). Historia de Macas. Cuenca: Centro Misional de Investigaciones Científicas (C.M.I.C.), Edit. Don Bosco. (1996). 100 años de trabajo educativo de la Misión Salesiana en Morona Santiago. En: Educación presente, pasado y futuro en Morona Santiago. Simposio Educativo con motivo de celebrarse 100 años de la Misión Salesiana y 500 años del encuentro de los dos mundos. Cuenca: Edibosco. shamanístico está ligada al intercambio de artículos occidentales" (Salazar, 1981). 
Bottasso, J. (1978). Un pasado en que hay que meditar. En: La Iglesia Shuar. Interrogantes y perspectivas. Sucúa: Colección Mundo Shuar, Serie B, fascículo 8.

(1982). Los Shuar y las Misiones: Entre la hostilidad y el diálogo. Quito: Fondo Internacional de Promoción de la Cultura, UNESCO, Mundo Shuar.

(Comp.) (1993). Los salesianos y la Amazonía. Tomo I: "Relaciones de viajes 1893-1909", Tomo II: "Relaciones etnográficas y geográficas”, Tomo III: “Actividades y presencias”. Quito: Abya-Yala.

(2003). Los salesianos y la lengua de los shuar En: Discurso de Incorporación a la Academia Nacional de Historia del Ecuador. Quito: Academia Nacional de Historia, Abya-Yala. (2011). Los salesianos y los Shuar. Quito: Abya-Yala.

Brito, E. (1935. Homenaje del Ecuador a Don Bosco Santo. Tomo Primero. La obra salesiana en el Ecuador (1888-1935). Quito: Escuela Tipográfica Salesiana.

Broseghini, S. (1978). La Iglesia Shuar. Nueva presencia y nuevo lenguaje. Mundo Shuar, II Edición, Serie B, fascículo 7, Sucúa. (1983). Cuatro siglos de misiones entre los shuar. Los métodos. Quito: Ediciones Mundo Shuar.

Carollo, L. (1987). Misiones en la Amazonía Ecuatoriana. Una centuria de luchas y conquistas en el Vicariato Apostólico de Méndez. En: Carlos Valverde (Ed.), Presencia Salesiana en el Ecuador. Primer Centenario 1888-1988. Cuenca: Edibosco.

Carrera, T. (1987). Historia de la tierra de los Macas. Tomo I. Macas: Imp. Edunica.

Colajanni, A. (2008). La actividad misionera salesiana entre los shuar del Ecuador, intereses antropológicos y estrategias de promoción del cambio sociocultural. En: Flavia Cuturi (Comp.), En Nombre de Dios. La empresa misionera frente a la alteridad. Quito: Abya-Yala.

Costales, P., \& Costales, A. (1978). Los shuar en la Historia. Sevilla de Oro y San Francisco de Borja. Sucúa: Mundo Shuar.

Esvertit Cobes, N. (2012). Los salesianos en el Vicariato apostólico de Méndez y Gualaquiza: Configuración territorial, colonización y nacionalización del Suroriente ecuatoriano, siglos XIX y XX. En: José Juncosa et al. (Coords.), La Presencia Salesiana en el Ecuador, perspectivas históricas y sociales, Segunda Edición. Quito: Universidad Politécnica Salesiana, Abya-Yala. 
Federación de Centros Shuar (1977). Organizarse o sucumbir. Centro de Documentación e Investigación Cultural Shuar. Colección Mundo Shuar, serie B, fascículo 14, Sucúa.

Germani, A. (Aij'Juank) (1977). La Educación Radiofónica Bicultural: cuaderno de pedagogía, didáctica y tecnología educativa. Mundo Shuar, Serie B, fascículo 10. Centro de Documentación e Investigación Cultural Shuar, Sucúa.

(1984). Pueblo de fuertes. Rasgos de la historia shuar. Tomos I y II. Quito: Abya-Yala.

Gnerre, M. (2012). Los salesianos y los shuar construyendo la identidad cultural. En: José Juncosa (Coord.), La Presencia Salesiana en el Ecuador, perspectivas históricas y sociales, Segunda Edición. Quito: Universidad Politécnica Salesiana, Abya-Yala.

Guerriero, A., \& y Creamer, P. (1997). Un siglo de presencia salesiana en el Ecuador. El proceso histórico 1888-1988. Quito.

Guerriero, A. (1944). Cincuenta años de Misión Salesiana en el Oriente Ecuatoriano Quito: AHMS.

González A. (2007). Historia de las Misiones en el Ecuador. Conferencia Episcopal ecuatoriana, versión digital. Quito.

Harner, M. (1978 [1994]). Shuar: Pueblo de las Cascadas Sagradas. Sucúa: Ediciones Mundo Shuar, 1978; Quito: Abya-Yala.

Jintiach' J. (1976). La integración del estudiante shuar en su comunidad, Colección Mundo Shuar, serie B, fascículo 4, Sucúa.

Münzel, M., \& Kroeger, A. (1981). El pueblo shuar de la leyenda al drama. Título original: Schrumpkopf-Macher? Jibaro Indianer in Südamerika. Ed. Museum F. Völkerkunde, Frankfurt, 1977, Traducción: Hajo Mertz-Lourdes Mujica, Mundo Shuar, Sucúa.

Ochoa, C., \& Sierra, L. M. (1976). Una comunidad shuar en proceso de cambio, Colección Mundo Shuar, Serie "B", fascículo 2, Centro de Documentación e Investigación Cultural Shuar, Sucúa.

Rubenstein, S. (2006). La conversión de los shuar. Iconos, Revista de Ciencias Sociales, 22. Quito: FLACSO.

Salazar, E. (1981). La Federación Shuar y la frontera de la colonización. En: Norman Whitten (Comp.), Amazonía Ecuatoriana. La otra cara del progreso. Ediciones Mundo Shuar, Sucúa. 